\title{
SÍNDROME DE BURNOUT EM PROFESSORES DE EDUCAÇÃO FÍSICA DA REGIÃO NORDESTE DO PARÁ
}

\author{
Daniel Alvarez Pires \\ Universidade Federal do Pará, Castanhal, Pará, Brasil \\ Paulo Augusto Pimentel Monteiro \\ Prefeitura Municipal de Terra Alta, Terra Alta, Pará, Brasil \\ Diego Rodrigues Alencar \\ Universidade Federal do Pará, Castanhal, Pará, Brasil
}

\begin{abstract}
Resumo
Os objetivos da pesquisa consistiram em mensurar as dimensões de Burnout em professores de Educação Física do nordeste do Pará, bem como comparar os índices entre os gêneros e entre os professores formados e em formação. A amostra foi composta por 40 docentes de Educação Física. Foram empregados o Maslach Burnout Inventory para educadores e um questionário sociodemográfico. Os dados foram analisados por meio de estatística descritiva e do teste $t$ de Student. Foram encontrados valores intermediários das dimensões de Burnout. Não foram encontradas diferenças significativas entre os gêneros, ao passo que os professores formados apresentaram maior valor de exaustão emocional. Os achados apontam maior possibilidade de desenvolvimento de Burnout em professores com formação superior.
\end{abstract}

Palavras-chave: Esgotamento Profissional. Educação Física e Treinamento. Docentes.

\section{Introdução: a síndrome de Burnout}

$\mathrm{O}$

Burnout relacionado ao ambiente de trabalho tem sido reconhecido como um risco para diversas profissões, principalmente nas denominadas profissões de ajuda, as quais envolvem serviços humanos, educação e saúde (MASLACH; GOLDBERG, 1998).

Nessa perspectiva, o Burnout foi discutido pela primeira vez em 1969, por Brandley, designando aquilo que deixou de funcionar por exaustão de energia (BENEVIDES-PEREIRA; GARCIA, 2003). No entanto, esse assunto tomou notoriedade mundial em 1974 e 1975 pelo psiquiatra Herbert Freudenberger e por Christina Maslach, em 1976. Desde então, suas características não passaram por mudanças significativas, as quais se enquadram na exaustão avassaladora, frustrações e sensações de insuficiência e ineficácia. Esses sentimentos afetam os 
aspectos pessoais e laborais do indivíduo. Dessa forma, essas manifestações prejudicam tanto esse indivíduo quanto as pessoas em sua rede social e de trabalho (MASLACH; GOLDBERG, 1998).

A expressão criada por Freudenberger $(1974,1975)$ com relação a essa síndrome foi denominada de staff Burnout, a qual era composta pela exaustão, desilusão e isolamento em trabalhadores da saúde mental.

De acordo com Maslach e Jackson (1981), o Burnout pode ser considerado uma resposta ao estresse emocional crônico e interpessoal no ambiente laboral, ou seja, uma experiência de estresse individual incorporado no contexto multidimensional das relações sociais, a qual acaba envolvendo as demais pessoas em seu ambiente de trabalho. Portanto, essas autoras definem o Burnout como uma síndrome psicológica de exaustão emocional, despersonalização e redução da realização pessoal, evidenciando seu caráter multidimensional.

A dimensão "exaustão emocional" representa a extensão do estresse básico do Burnout. Refere-se à sensação de estar esgotado tanto fisicamente quanto mentalmente, ao ponto de o trabalhador ter chegado ao seu limite de possibilidades, apresentando indisposição de energia para suas tarefas laborais (MASLACH; GOLDBERG, 1998).

A dimensão "despersonalização" representa o componente relativo às relações interpessoais do Burnout, destacando-se o contato insensível e impessoal com os usuários e companheiros de seus serviços, passando a expressar indiferença ao que pode vir a acontecer aos demais (MASLACH e GOLDBERG, 1998).

Por último, a dimensão "realização pessoal no trabalho" representa a autoavaliação do Burnout. Essa dimensão faz referência às sensações de insatisfação, baixa autoestima, incompetência, desmotivação e improdutividade relacionadas às atividades laborais que o profissional vem realizando (MASLACH; GOLDBERG, 1998).

Torna-se relevante observar que essas três dimensões caminham juntas. Os estudos realizados por Maslach e Goldberg (1998) afirmam que a exaustão emocional acarreta ao trabalhador a despersonalização, estabelecendo uma relação indiferente no seu ambiente de trabalho. A reduzida realização pessoal demonstra-se de uma forma mais complexa, pois se assemelha a uma função da exaustão emocional e da despersonalização, até mesmo a combinação de ambas (BYRNE, 1994). Nesse caso, torna-se difícil possuir um sentimento de realização profissional quando o trabalhador encontra-se esgotado emocionalmente. 
Outra tarefa difícil para o trabalhador desapontado com sua profissão é ajudar as pessoas que lhe são indiferentes.

\section{Principais instrumentos de mensuração}

O pioneirismo da construção e validação de um instrumento para esse fim ficou sob responsabilidade de Christina Maslach e Susan Jackson em 1981, que elaboraram o instrumento Maslach Burnout Inventory (MBI), o qual é considerado o instrumento universal para a identificação e mensuração dessa síndrome desde então (CABRERA; ELVIRA, 2004). De acordo com Biehl (2009), esse instrumento unificou as medidas que compreendiam o estresse crônico e fez emergir as três dimensões de Burnout: exaustão emocional, despersonalização e reduzida realização pessoal. Em sua primeira versão, o inventário possuía 47 itens que foram administrados em uma amostra de 605 sujeitos de várias ocupações profissionais (MALACH; JACKSON, 1981).

Há duas versões do MBI, as quais também são utilizadas em demasia nas pesquisas científicas: a original, Human Service Survey (HSS), mais adequada para prestadores de serviços, e a mais recente, General Survey (GS), que pode ser aplicada para uma ampla gama de profissões (CARLOTTO; CÂMARA, 2007).

A adaptação do MBI para os professores mais conhecida é a Educators Survey (ES), ou "MBI forma ED". Esse questionário é basicamente igual ao MBI, apenas houve a substituição da palavra "cliente" por "aluno", com o intuito de melhorar sua adaptação à população específica (BENEVIDES-PEREIRA et al. 2002).

\section{Sintomatologia}

Torna-se relevante ressaltar que qualquer atividade profissional pode vir a desencadear a síndrome de Burnout. No entanto, existem profissões que, por exigirem um contato maior de cunho emocional do profissional com seu cliente, acabam sendo consideradas predisponentes ao Burnout. De acordo com Benevides-Pereira (2002), as pessoas mais propensas ao processo de Burnout são as idealistas, altamente motivadas, identificadas com seu trabalho, empáticas e perfeccionistas, pois elas sentem uma frustração maior quando seus projetos fracassam. 
Segundo Benevides-Pereira (2002), não há uma experiência significativa no diagnóstico clínico diferencial ao se tratar do quadro de comorbidade com a depressão, pois ambos possuem em comum a disforia e o desânimo. A autora afirma que, nos casos de depressão, encontram-se a letargia e a predominância dos sentimentos de culpa e de derrota. Por outro lado, na síndrome de Burnout é verificada a decepção e a tristeza. A mesma autora contesta que, devido à falta de conhecimento e às semelhanças de sintomas, muitos professores são afastados de suas práticas pedagógicas por serem diagnosticados equivocadamente com depressão.

Devido a esses constantes equívocos clínicos, Benevides-Pereira (2002) elaborou um quadro que aborda de forma simples a sintomatologia da síndrome de Burnout, conforme descrito no Quadro 1:

\begin{tabular}{|c|l|}
\hline Sintomas & \multicolumn{1}{|c|}{ Características } \\
\hline Físicos & $\begin{array}{l}\text { Fadiga constante e progressiva, distúrbios do sono, dores } \\
\text { musculares ou osteomusculares, cefaleias, enxaquecas, perturbações } \\
\text { gastrointestinais, imunodeficiência, transtornos cardiovasculares, } \\
\text { distúrbios do sistema respiratório, disfunções sexuais e alterações } \\
\text { menstruais. }\end{array}$ \\
\hline Psíquicos & $\begin{array}{l}\text { Falta de atenção, de concentração, alterações de memória, } \\
\text { lentificação do pensamento, sentimento de alienação, sentimento de } \\
\text { solidão, impaciência, sentimento de insuficiência, baixa autoestima, } \\
\text { labilidade emocional, dificuldade de autoaceitação, astenia, } \\
\text { desânimo, disforia, depressão, desconfiança e paranoia. }\end{array}$ \\
\hline Comportamentais & $\begin{array}{l}\text { Negligência ou excesso de escrúpulos, irritabilidade, incremento da } \\
\text { agressividade, incapacidade para relaxar, dificuldade na aceitação } \\
\text { de mudanças, perda de iniciativa, aumento do consumo de } \\
\text { substâncias, comportamentos de alto risco e suicídio. }\end{array}$ \\
\hline Defensivos & $\begin{array}{l}\text { Tendência ao isolamento, sentimento de onipotência, perda do } \\
\text { interesse pelo trabalho (ou até pelo lazer), absenteísmo, ironia e } \\
\text { cinismo. }\end{array}$ \\
\hline
\end{tabular}

Quadro 1: Sintomatologia da síndrome de Burnout

Fonte: Benevides-Pereira (2002, p. 44).

\section{Burnout em professores}

Considerando as significativas mudanças ocorridas na educação, especialmente nas últimas décadas, os professores passaram a preocupar-se mais intensamente com questões que vão além de suas funções docentes, como sua carreira, sua segurança e seu salário, além de atribuições como trabalhos administrativos, preenchimento de relatórios, reuniões de coordenação, conselhos de classe, entre outras. Desse modo, entende-se que, no modelo atual, são muitas as atribuições im- 
postas ao professor, alheias a seu interesse e muitas vezes a sua carga horária (CARLOTTO, 2002).

Diante de tamanha cobrança, muitos professores sentem-se exauridos, angustiados e até mesmo desvalorizados, tendo que ocupar parte de seu tempo livre com atividades relacionadas a seu trabalho. Além do que, em seu ambiente laboral, deparam-se diariamente com alunos desinteressados, evasivos, descompromissados. Todos esses fatores despertam no professor sentimentos negativos em relação a sua prática docente, podendo, dessa forma, desenvolver sintomas que indiquem a incidência da síndrome de Burnout.

O Burnout em professores afeta o ambiente educacional, interferindo na obtenção dos objetivos pedagógicos, podendo induzir esses profissionais a um processo de alienação, desumanização e apatia no trabalho, acarretando problemas de saúde, absenteísmo e intenção de desistir da profissão (GUGLIELMI; TATROW, 1998). Nessa perspectiva, o Burnout interfere nas relações interpessoais dos professores no ambiente escolar, seja com os colegas de profissão, corpo técnico ou com os próprios alunos, tornando-os impessoais e desinteressados.

No entanto, existem outros fatores a considerar quando falamos em professores, de modo que não pertencem a um grupo homogêneo, pois dentro dessa categorização há diferenças nas funções e atribuições. Sendo assim, o trabalho desenvolvido também apresenta diferentes desafios, demandas e recompensas, dependendo de variáveis como nível de ensino, tipo de instituição (pública ou privada, urbana ou rural), faixa etária dos alunos, contexto social, entre outras (CARLOTTO, 2002). Diante desse cenário, pode-se afirmar que os professores de Educação Física, objeto de estudo deste trabalho, encontram-se também expostos ao desenvolvimento da síndrome.

Segundo Santini e Molina Neto (2005), um fator determinante para o desenvolvimento de sentimentos negativos relacionados ao ambiente de trabalho é a formação acadêmica precária, pois, segundo relatos encontrados em seu estudo, afirmam que a relação entre teoria e prática no período de formação do professor é tratada de maneira muito distante, preocupando-se com a prática em detrimento da teoria. De acordo com relatos deste estudo, apesar de a formação inicial ter influência significativa na prática pedagógica, ela não prepara o professor para os reais desafios encontrados no cotidiano escolar.

Um desafio à realização da prática pedagógica encontrado pelo professor de Educação Física é a organização do espaço físico desti- 
nado as suas aulas e a precária condição no que se refere a recursos materiais. Nesse contexto, o professor se vê obrigado a ministrar suas aulas em espaços abertos, expostos a constantes mudanças climáticas. Tais situações podem gerar desgaste emocional e psicológico no professor, acarretando prejuízos a sua prática pedagógica (SANTINI; MOLINA NETO, 2005).

O estado do Pará, na Região Norte do Brasil, possui deficiência no número de professores licenciados. Para suprir essa demanda, que também ocorre em outros estados, foi criado o Plano Nacional de Formação de Professores da Educação Básica (Parfor), destinado aos professores em exercício das escolas públicas estaduais e municipais sem formação adequada à Lei de Diretrizes e Bases da Educação Nacional. O Parfor oferece cursos superiores públicos e gratuitos, com a oferta cobrindo os municípios de 21 estados, por meio de 76 instituições públicas de educação superior. A oferta do curso de licenciatura em Educação Física do Parfor pela Universidade Federal do Pará (UFPA) acontece na modalidade presencial e é realizada em algumas cidades-polo, como Castanhal e Bragança.

Atualmente, frente aos avanços em ciência e tecnologia e à necessidade de mão de obra mais especializada, entende-se que é preciso ter uma educação de qualidade. Diante disso, o professor torna-se ainda mais importante e requisitado. Entretanto, a categoria docente vem sendo apontada como uma das mais propensas ao estresse e Burnout (BENEVIDES-PEREIRA et al., 2002), por motivos como a falta de estrutura no ambiente laboral, formação acadêmica limitada e alunos pouco envolvidos com o processo de ensino-aprendizagem.

Desse modo, é possível perceber que o ensino acaba se tornando uma área de atuação potencialmente propícia ao desenvolvimento de características relacionadas ao Burnout, podendo levar ao desenvolvimento da síndrome se não houver acompanhamento adequado.

Nesse sentido, sendo os professores responsáveis por parcela significativa da formação humana, acredita-se que seja necessário problematizar a síndrome de Burnout no meio educacional e fazer um levantamento de dados da situação na qual se encontram esses profissionais em relação à síndrome, pois, além de ser pouco conhecida entre os profissionais da educação, é também pouco difundida e discutida no âmbito acadêmico nacional. 


\section{Problema}

Percebe-se que a relevância profissional exercida pelo docente está sendo sufocada pelas inúmeras mazelas que o acompanham. Jasiulionis (2009) discorre sobre esse assunto da seguinte forma: para o exercício de ensinar é exigida uma dedicação estável e permanente dos alunos, sua família e da própria sociedade; o professor, seja da rede pública ou privada de ensino, encontra-se em uma situação densa de compromissos, os quais envolvem seu ambiente laboral, sua vida particular e o contexto governamental no qual está inserido.

Ao se avaliar esses problemas, destacam-se aqueles envolvidos no ambiente laboral, como as metas irrealistas dos professores relacionadas aos seus objetivos profissionais, podendo frustrar-se quando suas metas não são concretizadas. Santini e Molina Neto (2005) apontam, ainda, as dificuldades e limitações durante a formação acadêmica desses futuros professores como um dos fatores determinantes para a sua insatisfação e insucesso profissional, pois existem, durante a graduação, carências na formação pedagógica dos alunos, tanto nos estágios quanto no início de sua carreira docente, as quais acarretam influências substanciais na percepção dos resultados laborais.

Outra característica é a baixa remuneração. Para compensá-la, geralmente o professor aumenta sua carga horária e procura outro emprego. Por consequência, o tempo disponível para a elaboração e avaliação das aulas e construção de grupos de pesquisa e discussão passa a ser escasso (BOTH et al., 2008).

Essas e outras mazelas acompanham a vida do professor, interferindo em sua prática pedagógica e ocasionando até mesmo diversos problemas em sua saúde, como a síndrome de Burnout, a qual demonstra ser um fenômeno multidimensional, ocasionada pela interação entre os aspectos pessoais e laborais (CARLOTTO, 2002).

\section{Objetivo geral}

Mensurar os índices da síndrome de Burnout e de suas dimensões em professores de Educação Física escolar na região nordeste paraense.

Pensar a Prática, Goiânia, v. 15, n. 4, p. 821-1113, out./dez. 2012 


\section{Objetivos específicos}

Verificar a associação entre variáveis de sexo (masculino e feminino) e os níveis das dimensões da síndrome de Burnout.

Verificar a associação entre variáveis de titulação (professores formados e os em formação) e as dimensões da síndrome de Burnout.

\section{Método: amostra e procedimentos éticos}

Esta pesquisa contou com uma amostra de 40 professores, de ambos os sexos, sendo 18 homens e 22 mulheres que lecionam a disciplina Educação Física em cidades do nordeste do Pará. Os participantes desta pesquisa foram divididos em dois grupos de 20 professores. O primeiro grupo foi composto por 8 homens e $12 \mathrm{mu}$ lheres que possuem licenciatura em Educação Física e atuam em escolas públicas e/ou particulares do município de Castanhal. Constituíram o segundo grupo 10 homens e 10 mulheres participantes do Plano Nacional de Formação dos Professores da Educação Básica (Parfor) nas cidades-polo de Castanhal e Bragança. Estudam nesses polos os professores em formação oriundos das seguintes cidades da região nordeste do Pará: Augusto Corrêa, Bragança, Capanema, Castanhal, Irituia, Maracanã, Nova Timboteua, Rondon do Pará, Santa Luzia do Pará, Viseu e Quatipuru.

Este estudo respeita as normas estabelecidas pela Resolução 196/96 do Conselho Nacional de Saúde, envolvendo pesquisas com seres humanos. Todos os participantes assinaram o Termo de Consentimento Livre e Esclarecido (TCLE), declarando estar de acordo com sua participação no estudo.

\section{Instrumentos}

Para a realização desta pesquisa de corte transversal, foi utilizado o questionário adaptado do MBI para os professores: o Educators Survey (ES), que, na forma traduzida para o português, denomina-se "MBI forma ED", ou seja, MBI para educadores. O questionário original foi elaborado por Maslach e Leiter e validado internacionalmente por Maslach, Jackson e Leiter (FERENHOF; FERENHOF, 2002). A tradução deste questionário para a aplicação na população brasileira foi realizada pelo Grupo de Estudos e Pesquisas sobre Estresse e Bur- 
nout (Gepeb), do Departamento de Psicologia da Universidade Estadual de Maringá, coordenado pela professora Ana Maria BenevidesPereira (BENEVIDES-PEREIRA; GARCIA, 2003).

Aplicável a professores com o objetivo de acessar os valores de cada dimensão da síndrome de Burnout, o MBI-ED mensura três dimensões: exaustão emocional, despersonalização e realização pessoal no trabalho. A dimensão "exaustão emocional" possui nove itens e permite acessar os sentimentos de estar emocionalmente sobrecarregado e exausto pelo trabalho. A dimensão "despersonalização", com cinco itens, mede a resposta insensível e impessoal direcionada pelo profissional ao seu aluno. Quanto mais elevados os índices nessas duas dimensões, maior o nível da síndrome de Burnout. Os oito itens da dimensão "realização pessoal no trabalho" permitem acessar sentimentos de competência e sucesso no trabalho. Em contraste com as demais dimensões, um baixo índice nessa dimensão representa um alto nível da síndrome de Burnout (MASLACH; JACKSON, 1981).

Cada item é avaliado em uma escala Likert de 0 a 6, de acordo com a frequência que o professor sente cada situação apresentada: "nunca" (0); "algumas vezes ao ano ou menos" (1); "uma vez ao mês ou menos" (2); "algumas vezes durante o mês" (3); "uma vez por semana" (4); "algumas vezes durante a semana" (5); e "todo dia" (6).

Um questionário sociodemográfico com 15 itens também foi aplicado na pesquisa para o levantamento de aspectos inerentes aos participantes do estudo (sexo, idade, tempo de profissão, satisfação salarial).

\section{Procedimentos}

A aplicação dos questionários para esta pesquisa ocorreu durante os meses de julho a outubro de 2010. Os professores do grupo Parfor responderam ao instrumento durante as aulas presenciais nas cidadespolo de Castanhal e Bragança.

As coletas envolvendo os professores licenciados ocorreram no município de Castanhal. Os pesquisadores responsáveis visitaram escolas públicas e particulares desse município. Após entrarem em contato com os professores de Educação Física de cada instituição de ensino, estes eram informados sobre os objetivos da pesquisa, bem como sobre o anonimato e confidencialidade das respostas. 
Em ambos os grupos (Parfor e licenciados), os professores responderam ao Termo de Consentimento Livre e Esclarecido (TCLE), ao questionário sociodemográfico e ao questionário MBI na forma ED.

\section{Análise de dados}

Para o cálculo dos dados sociodemográficos e das dimensões de Burnout, foi utilizada a estatística descritiva, a partir dos cálculos das médias e desvio padrão. Os valores absolutos demonstraram a soma das respostas numéricas de cada dimensão (exaustão emocional, despersonalização e realização pessoal) e foram analisados de acordo com a classificação (baixo, médio ou alto) definida por BenevidesPereira e Garcia (2003).

Para realizar a comparação entre os grupos masculino $\mathrm{x}$ feminino e formados x em formação, foi utilizado o teste $t$ de Student por meio do software Bioestat 5.0 ® . O nível de significância adotado foi de $p$ $<0,05$.

\section{Resultados e discussão: caracterização da amostra}

A idade dos participantes do sexo masculino variou entre 26 e 50 anos, com uma média de 34,5 $\pm 6,7$ anos. A variação de idades dos participantes do sexo feminino foi de 23 a 54 anos, com média de $34,0 \pm 7,7$ anos.

Entre os homens, 12 atuam somente em escolas públicas, 1 atua somente em escolas particulares e 5 atuam em escolas públicas e particulares. Entre as mulheres, 16 atuam somente em escolas públicas, 3 atuam somente em escolas particulares e 3 atuam em escolas públicas e particulares.

Em relação ao tempo de profissão, 4 homens possuem de 0 a 5 anos de profissão, 10 homens possuem de 6 a 11 anos de profissão, 3 homens possuem de 12 a 17 anos de profissão, e 1 homem possui de 18 ou mais anos de profissão. Entre as professoras, 8 mulheres possuem de 0 a 5 anos de profissão, 6 mulheres possuem de 6 a 11 anos de profissão, 5 mulheres possuem de 12 a 17 anos de profissão, 3 mulheres possuem 18 anos ou mais.

A respeito da satisfação salarial, 4 homens estão satisfeitos com o salário que recebem e 14 não estão satisfeitos. Entre as mulheres, 5 estão satisfeitas com o salário que recebem e 17 não estão satisfeitas. 


\section{Dimensões de Burnout na amostra total}

A tabela 1 apresenta os valores médios de todos os professores formados e em formação de ambos os sexos. Os resultados desta amostra foram classificados de acordo com os critérios definidos por Benevides-Pereira e Garcia (2003) dispostos no Quadro 2.

Tabela 1: Índices das dimensões de Burnout obtidos na amostra total

\begin{tabular}{|l|l|l|l|}
\hline Dimensões & Média & Desvio padrão & Classificação \\
\hline Exaustão emocional & 17,6 & 8,9 & Médio \\
\hline Realização pessoal & 36,1 & 7,4 & Médio \\
\hline Despersonalização & 3,6 & 3,9 & Médio \\
\hline
\end{tabular}

\begin{tabular}{|l|l|l|l|}
\hline Dimensão & Baixo & Médio & Alto \\
\hline Exaustão emocional & Abaixo de 15 & $16-25$ & A partir de 26 \\
\hline Despersonalização & Abaixo de 2 & $3-8$ & A partir de 9 \\
\hline Realização pessoal & Abaixo de 33 & $34-42$ & A partir de 43 \\
\hline
\end{tabular}

Quadro 2: Classificação dos índices das dimensões de Burnout Fonte: Adaptado de Benevides-Pereira e Garcia (2003).

Os resultados encontrados nesta pesquisa podem estar associados à forma e ao conteúdo das perguntas apresentadas tanto no questionário MBI-ED quanto no questionário sociodemográfico, pois, segundo Benevides-Pereira (2002), algumas questões do MBI podem ocasionar nos professores um impacto negativo, já que algumas indagações contidas no inventário refletem uma postura contraditória esperada por um professor. Portanto, pode ter sido difícil para o professor revelar certas atitudes ocasionadas em seu ambiente laboral, tais como tratar seus alunos de forma impessoal, que é uma expectativa nunca esperada pelos pais, pela administração escolar e pela sociedade em geral, e que não faz parte do perfil idealizado do professor.

\section{Índices das dimensões entre os gêneros}

Os índices de exaustão emocional dos professores dos gêneros masculino e feminino estão representados no Gráfico 1. Os professores do gênero masculino obtiveram a média de $18,2 \pm 8,2$, considerado um valor médio, de acordo com o Quadro 3. A amostra feminina obteve média igual a 17,2 \pm 9,2, caracterizando um nível médio. 


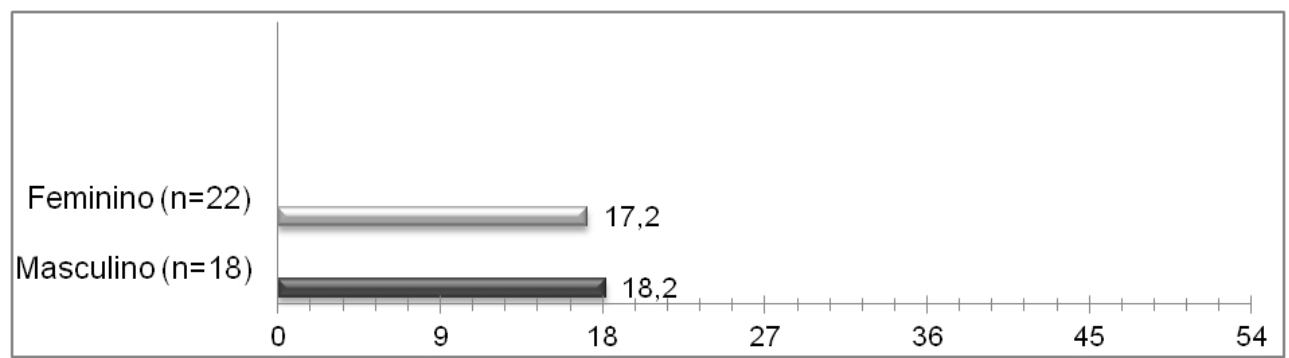

Gráfico 1: Níveis de exaustão emocional para professores homens e mulheres $(\mathrm{n}=40)$

Representada no Gráfico 2, a dimensão "despersonalização" evidencia que os professores do gênero masculino alcançaram uma média igual a 4,0 $\pm 3,5$, caracterizando esta dimensão no nível médio do MBI, estabelecido no Quadro 13. O grupo feminino obteve nos valores absolutos uma média de $3,6 \pm 4,3$, a qual expressa para essa dimensão um nível médio no MBI.

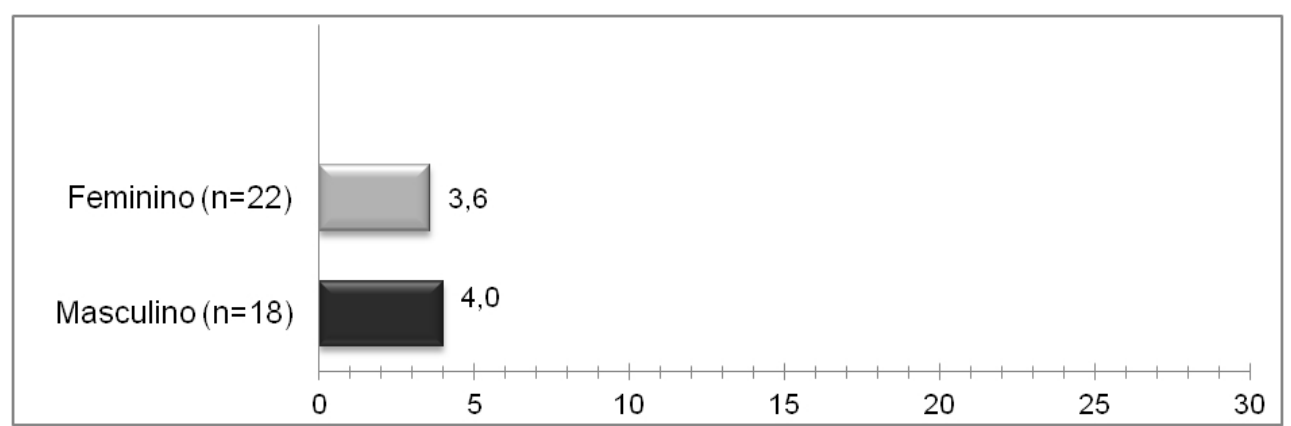

Gráfico 2: Níveis de despersonalização para professores homens e mulheres $(\mathrm{n}=40)$

A dimensão "realização pessoal", expressa no Gráfico 3, evidencia nos valores absolutos para o grupo masculino uma média igual $36,7 \pm$ de 6,1. Portanto, esse grupo apresentou resultado considerado como médio, de acordo com o Quadro 3. O grupo feminino apresentou média igual a $35,2 \pm 8,2$, índice também avaliado como médio.

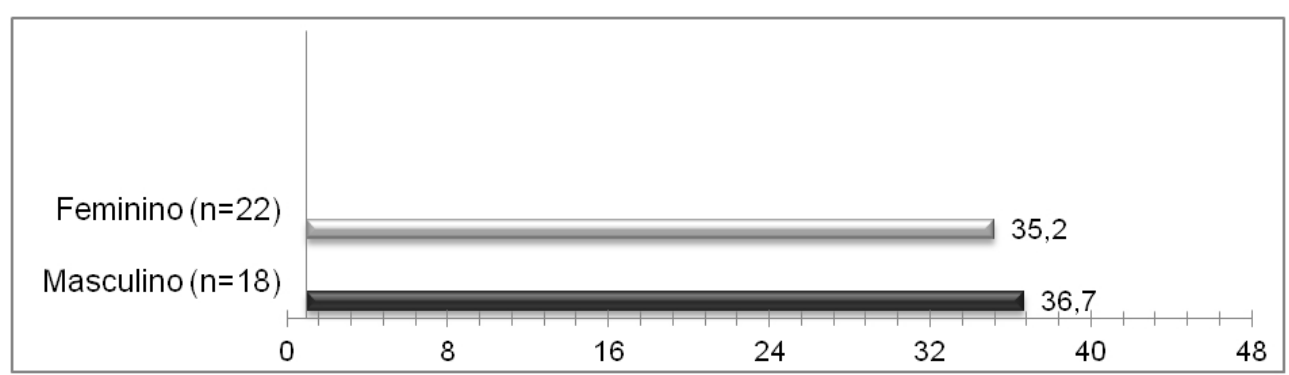

Gráfico 3: Níveis de realização pessoal para professores homens e mulheres $(n=40)$

Pensar a Prática, Goiânia, v. 15, n. 4, p. 821-1113, out./dez. 2012 
Sobre a manifestação de Burnout em professores, Benevides-Pereira $(2002$, p. 52) afirma que "não tem havido unanimidade quanto à possibilidade de maior incidência no que diz respeito ao sexo". Portanto, os resultados encontrados corroboram essa afirmação, ou seja, não se confirma a prevalência da síndrome em nenhum dos gêneros, visto que os escores não apresentaram diferenças estatisticamente significativas entre os sexos nas três dimensões investigadas.

Nas análises entre os escores encontrados nas três dimensões e a variável gênero é comum, de acordo com Maslach e Jackson (1981), não encontrar diferenças estatisticamente significativas. Portanto, os resultados encontrados estão de acordo com a literatura, pois as variáveis demográficas como gênero, idade, estado civil e o fato de ter filhos não possuem poderes preditivos e associações com o Burnout (MASLACH; SCHAUFELI; LEITER, 2001).

\section{Índices das dimensões entre professores formados e em formação}

Na dimensão "exaustão emocional", representada no Gráfico 4, os professores formados obtiveram média de 20,7 $\pm 9,6$ nos valores absolutos, encontrando o grupo, dessa forma, com o nível médio nessa dimensão no MBI, de acordo com o Quadro 3. A amostra referente aos não formados apresentou uma média igual a 14,6 \pm 7,2 nos valores absolutos, indicando que esse grupo se encontra com nível classificado como baixo para essa dimensão. Destaca-se que essa dimensão possui uma diferença estatisticamente significativa, com $\mathrm{p}<0,05$.

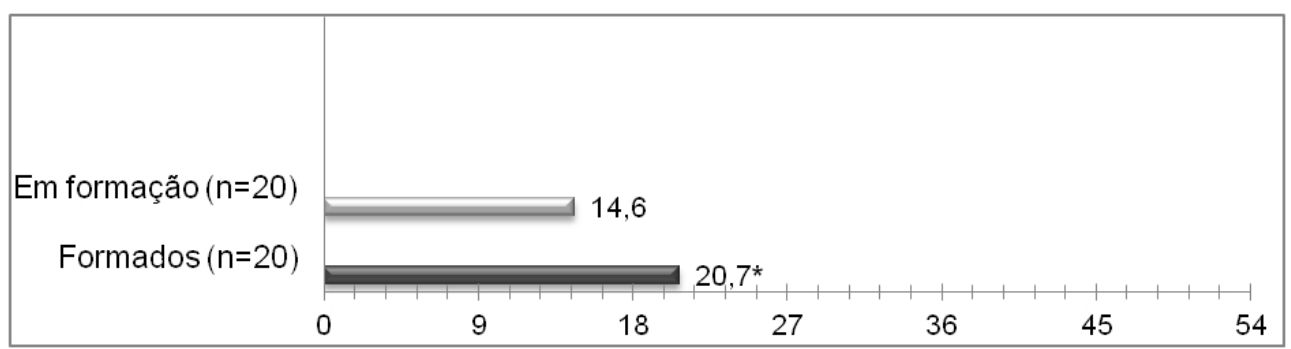

Gráfico 4: Níveis de exaustão emocional para professores formados e em formação $(\mathrm{n}=40)$

*Essa dimensão apresentou diferença estatisticamente significativa $(\mathrm{p}=0,02)$.

O Gráfico 5 apresenta os dados referentes à dimensão "despersonalização". Os professores formados apresentaram média de 4,2 $\pm 4,7$, resultado considerado médio para a dimensão, de acordo com o Quadro 3. A amostra referente ao grupo de professores em formação apre- 
sentou média igual a $3,1 \pm 3,0$, portanto esse grupo também apresenta índice considerado médio.

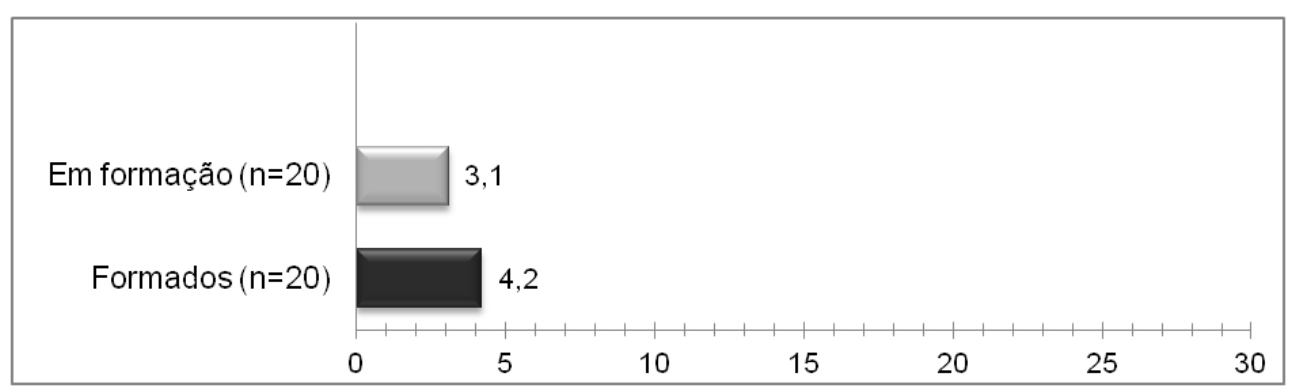

Gráfico 5: Níveis de despersonalização para professores formados e em formação $(\mathrm{n}=40)$

O Gráfico 6 evidencia os dados referentes à dimensão "realização pessoal", apresentando na amostra de professores formados média igual a $35,7 \pm 6,6$ nos valores absolutos. O grupo apresenta escores classificados como médios para essa dimensão, segundo o Quadro 3. A amostra relativa aos professores em formação apresentou valor absoluto médio igual a $36,5 \pm 8,3$, estando esse valor classificado como médio para a dimensão.

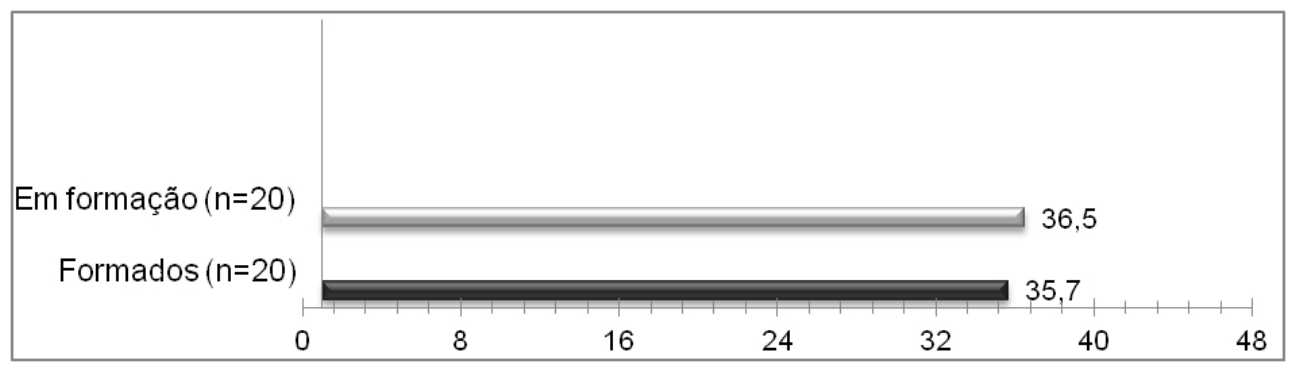

Gráfico 6: Níveis de realização pessoal para professores formados e em formação $(\mathrm{n}=40)$

Os resultados encontrados na relação entre professores formados e em formação apresentam nas três dimensões valores considerados intermediários, com exceção do resultado apresentado pelo grupo em formação na dimensão "exaustão emocional", a qual se apresentou com o nível baixo. Nessa mesma dimensão, foi detectada uma diferença estatisticamente significativa $(\mathrm{p}<0,05)$ entre os grupos. De acordo com Maslach (1982), esses resultados demonstram uma possibilidade mais acentuada do desenvolvimento da síndrome de Burnout referente aos professores formados, enquanto que seus pares em formação encontram-se abaixo da média na dimensão considerada como possuidora de um valor desencadeador de Burnout. 
Os resultados corroboram o estudo realizado por Maslach, Schaufeli, Leiter (2001), o qual demonstra que, geralmente, professores com formação superior podem apresentar níveis mais elevados de Burnout em relação a professores com menor titulação. As autoras afirmam que pessoas com ensino superior possuem empregos com maiores responsabilidades e maior estresse. No entanto, as autoras ressaltam que as discussões sobre a interferência dessa variável na incidência de Burnout apresentam resultados bastante incertos.

Outro fator que pode estar associado ao resultado diz respeito ao processo de formação docente. No início, o professor alimenta expectativas a respeito de sua prática pedagógica. Porém, ao encontrar condições adversas de trabalho, espaços sucateados, material pedagógico insuficiente e alunos desinteressados, o choque de realidades pode torná-lo vulnerável e propenso a desenvolver características indicativas da síndrome. Ferreira e Azzi (2010) argumentam que as condições precárias do trabalho docente facilitam o desenvolvimento de doenças ocupacionais, em especial o Burnout, contribuindo para o abandono da profissão nos anos iniciais de carreira e para a não escolha da função como atividade profissional.

\section{Considerações finais}

$\mathrm{Na}$ análise da amostra total, os índices das três dimensões foram classificados como intermediários. Ao fragmentar a amostra total de acordo com o gênero, observa-se que não houve, entre as dimensões da síndrome, valores com diferenças estatisticamente significativas, e os índices das dimensões foram classificados como médios. Quanto ao grau de formação, detectou-se que o grupo dos professores formados apresentou índices de exaustão emocional significativamente mais elevados que seus pares em formação, já as dimensões restantes apresentaram valores caracterizados como médios.

Apesar de ser discutida desde 1969, a síndrome de Burnout ainda é pouco conhecida, debatida e prevenida pelos professores. Ressalta-se que, com essa falta de conhecimento, os indicativos da doença surgem de forma "silenciosa" e gradualmente consomem a capacidade máxima da demanda suportada pelo professor.

Portanto, torna-se imprescindível a necessidade de realização de outras pesquisas sobre esse tema no âmbito acadêmico e escolar, para que possa haver maior compreensão da síndrome, bem como o esta- 
belecimento de métodos e práticas preventivas, pois o surgimento do Burnout em professores é um fator limitante em sua prática pedagógica e nas relações interpessoais tanto com seus companheiros de profissão quanto com seus alunos.

\title{
Burnout syndrome in teachers from Pará northeast region
}

\begin{abstract}
The purposes of the study were to measure the Burnout dimensions in Physical Education teachers from the Northeast Region of Pará State, as well as to compare the levels between genders and between graduated and undergraduate teachers. The sample consisted of 40 Physical Education teachers. Participants completed the Maslach Burnout Inventory - Educators Survey (MBI-ES) and a demographic questionnaire. Data were analyzed by descriptive statistics and Student's t test. Intermediary Burnout dimensions levels were found. No gender differences were found. Graduated teachers scored higher for emotional exhaustion dimension. The results suggest a higher risk of Burnout development in graduated teachers.
\end{abstract}

Keywords: Burnout. Physical Education. Teachers.

\section{La síndrome del Burnout en profesores de la región nordeste del Pará}

\section{Resumen}

Los objetivos de la investigación consistieron en medir las dimensiones del Burnout en profesores de Educación Física en el nordeste del Pará, y para comparar las tasas entre los sexos y entre los maestros capacitados y en formación. La muestra está compuesta por 40 profesores de Educación Física. Se utilizó el Maslach Burnout Inventory para educadores y un cuestionario socio demográfico. Los datos fueron analizados utilizando estadística descriptiva y la prueba t de Student. Encontraron valores intermedios de las dimensiones del Burnout. No hubo diferencias significativas entre los sexos, mientras que los maestros capacitados tenían un valor más elevado de agotamiento emocional. Estos resultados indican una mayor posibilidad de desarrollo de burnout en profesores con grado superior.

Palabras clave: Agotamiento Profesional. Educación y Entrenamiento Físico. Docentes.

\section{Referências}

BENEVIDES-PEREIRA, A. M. O processo de adoecer pelo trabalho. In: _ (Org.). Burnout: quando o trabalho ameaça o bem-estar do trabalhador. São Paulo: Casa do Psicólogo, 2002.

. et al. A avaliação do Burnout em professores: comparação de instrumentos CBP-R e MBI-ED. Psicologia em Estudo, Maringá, v. 7, n. 1, p. 11-19, 2002. 
; GARCIA, L. P. Investigando o Burnout em Professores Universitários. Revista Eletrônica Inter Ação Psy, v. 1, n. 1, p. 7689, 2003.

BIEHL, K. A. Burnout em Psicólogos. 2009. Tese (Doutorado em Psicologia). Faculdade de Psicologia, Pontifícia Universidade Católica do Rio Grande do Sul (PUC-RS), Porto Alegre, 2009.

BOTH, J. et al. Carreira docente em Educação Física: uma abordagem sobre a qualidade de vida no trabalho de professores da rede estadual de ensino do Rio Grande do Sul. Revista da Educação Física da UEM, Maringá, v. 19, n. 1, p. 11-22, 2008.

BYRNE, B. M. Burnout: testing for the validity, replication, and invariance of causal structure across elementary, intermediate and secondary teachers. American Educational Research Journal, Thousand Oaks, v. 31, n. 3, p. 645-673, set., 1994.

CABRERA, J. H.; ELVIRA, J. A. M. Estrés y burnout en profesores. International Journal of Clinical and Health Psychology, Granada, v. 4, n. 3, p. 597-621, set., 2004.

CARLOTTO, M. S. A Síndrome de Burnout e o trabalho docente. Psicologia em Estudo, Maringá, v. 7, n. 1, p. 21-29, 2002.

; CÂMARA, S. G. Propriedades psicométricas do Maslach Burnout Inventory em uma amostra multifuncional. Estudos de Psicologia, Campinas, v. 24, n. 3, p. 325-332, 2007.

FERENHOF, I. A.; FERENHOF, E. A. Burnout em Professores. ECCOS Revista Científica, São Paulo, v. 4, n. 1, p. 131-151, 2002.

FERREIRA, L. C.; AZZI, R. G. Docência, Burnout e Considerações da Teoria da Auto-eficácia. Psicologia: Ensino \& Formação, Brasília, v. 1, n. 2, p. 23-34, 2010.

FREUDENBERGER, H. J. Staff Burn-Out. Journal of Social Issues, Malden, v. 30, n. 1, p. 159-165, 1974.

. The Staff Burn-Out Syndrome in Alternative Institutions. Psychotherapy: theory, research and practice, Washington, v. 12, n. 1, p. 73-82, 1975. 
GUGLIELMI, R. S.; TATROW, K. Occupational stress, burnout, and health in teachers: a methodological and theoretical analysis. Review of Educational Research, Thousand Oaks, v. 68, n. 1, p. 61-69, 1998.

JASIULIONIS, H. Estudo dos fatores associados às dimensões da Síndrome de Burnout em uma amostra de professores de escolas da rede pública estadual de ensino da cidade de Sumaré, SP, Brasil. 2009. Dissertação (Mestrado em Saúde Coletiva) Faculdade de Ciências Médicas, Unicamp, Campinas, 2009.

MASLACH, C. Burnout: the cost of caring. Englewood Cliffs: Prentice Hall, 1982.

; GOLDBERG, J. Prevention of burnout: new perspectives. Applied \& Preventive Psychology. London, v. 7, p. 63-74, 1998.

; JACKSON, S. The Measurement of Experienced Burnout. Journal of Occupational Behaviour, Hoboken, v. 2, p. 99-113, 1981.

; SCHALFELI, W. B.; LEITER M. P. Job Burnout. Annual Review of Psychology, Palo Alto, v. 52, p. 397-422, 2001.

SANTINI, J.; MOLINA NETO, V. A síndrome do esgotamento profissional em professores de educação física: um estudo na rede municipal de ensino de Porto Alegre. Revista Brasileira de Educação Física e Esporte, São Paulo, v. 19, n. 3, p. 209-222, 2005.

Recebido em: 20/09/2011

Revisado em: 09/01/2012

Aprovado em: 18/05/2012

Endereço para correspondência

Daniel Alvarez Pires

danielpires@ufpa.br

Universidade Federal do Pará, Campus Universitário de Castanhal - CUNCAST.

Avenida dos Universitários, s/n

Jaderlândia

68746-360 - Castanhal, PA - Brasil 